\title{
The flipped classroom: supporting a diverse group of students in their learning
}

\author{
N. S. Goedhart ${ }^{1}$ (D) $\cdot$ N. Blignaut-van Westrhenen ${ }^{1} \cdot$ C. Moser ${ }^{2} \cdot$ M. B. M. Zweekhorst ${ }^{1}$
}

Received: 22 December 2017 / Accepted: 13 February 2019 / Published online: 7 March 2019

(c) The Author(s) 2019

\begin{abstract}
Higher education faces several challenges including both increased student diversity and the use of technologies. The flipped classroom approach has been proposed as a way to address some of these challenges. This study examined the effects of a flipped classroom trial conducted during a Master's course at the Vrije Universiteit Amsterdam in the Netherlands. Half of the course was taught in a traditional lecture style while the remaining half was replaced by flipped classrooms. Interviews and focus-group discussions were conducted with the students to gather information about their experiences of the flipped classroom. Questionnaires completed by the students, as well as an interview with the tutor, were used to gain further insights into the effects of the flipped classroom on learning processes, such as pre-class preparation and in-class activities. Findings highlight the success of this trial based on the positive feedback from both students and the tutor. In particular, the combination of personalised pre-class learning and peer-learning classroom activities facilitated deeper learning. Surprisingly, even though the overall experience was good, not all students agreed that the flipped classroom contributed to positive learning outcomes, which should be investigated further because such outcomes could differ depending on students' general learning styles and preferences. Moreover, in order to facilitate flipped classrooms on a larger scale, considerable institutional support is required to enable their practical implementation and to provide flexible assessments. Our study thus sheds light on the feasibility of implementing flipped classroom teaching in higher education.
\end{abstract}

Keywords Blended learning · Cognitive load · Diversity $\cdot$ Flipped classroom · Higher education $\cdot$ Peer-learning

\section{Introduction}

Worldwide there has been an increase in university student numbers (UNESCO 2017). In parallel, technological advances have changed the educational landscape because they impact on almost every facet of modern culture (Gajjar 2013). Diversity in students'

N. S. Goedhart

n.s.goedhart@vu.nl

Athena Institute, Faculty of Science, Vrije Universiteit, Amsterdam, The Netherlands

2 Faculty of Social Sciences, Vrije Universiteit, Amsterdam, The Netherlands 
learning styles and motivation challenges university tutors to provide education that leads to optimal performance for each individual student (Abeysekera and Dawson 2015; Cruzado and Román 2015). Considering these changes and challenges, educators have been asking whether the traditional lecture is still preferable and achieves the desired results. In response to these changes, new and different teaching methods have been proposed, such as blended learning.

One teaching method that has increasingly attracted university lecturers' interest and has the potential to serve a diverse student population is the inverted or flipped classroom (Abeysekera and Dawson 2015; Cruzado and Román 2015; O’Flaherty and Phillips 2015). While there is no universal definition, the core idea of the flipped classroom is to shift learning by transmitting information to before class, in the form of instructional videos, recorded lectures and other remotely-accessible pedagogical resources. A wide array of methods such as online videos, PowerPoints and online games can be used for pre-class preparation, whereby students learn in a reflective and self-paced manner (O'Flaherty and Phillips 2015). Subsequently, tutors spend in-class time applying the material through complex problem solving, deeper conceptual coverage and peer interaction (Gajjar 2013; O'Flaherty and Phillips 2015; Strayer 2012; Tucker 2012). Although the flipped classroom can be organized in learning environments that are not reliant on technology, it was mainly introduced in a type of blended or hybrid learning that combines direct and virtual sessions (Skill and Young 2002).

The diversity in students' prior knowledge is one of the most important considerations for course designers (Clark et al. 2011). The flipped classroom can provide opportunities to tailor the learning process to the diversity in students' expertise and learning styles through several learning processes and activities. For instance, by moving information transmission outside the classroom setting, students can work at their own pace at home, and tutors can provide multiple versions and formats (e.g. readings, videos) of difficult material tailored to students' diverse learning styles or prior knowledge (Abeysekera and Dawson 2015). Furthermore, pre-class activities (e.g. pre-class quizzes or assignments) can help educators to tailor activities to the individual student's expertise.

By tailoring pre-class activities to the students' diversity, and providing materials that can be viewed at students' own pace and frequency, university tutors can also help students in the flipped classroom to manage their cognitive load (Abeysekera and Dawson 2015). This has been found to make an important contribution to successful study (Clark et al. 2011). Cognitive load theory (CLT) posits that, because overloading student's working memory impedes learning, it is beneficial for students to work at their own pace (Clark et al. 2011). Our working memory is subject to three types of load: intrinsic cognitive, extraneous cognitive and germane cognitive load. Intrinsic cognitive load is the demand made of a student by the unchangeable core of a learning task, and depends both on its complexity and the students' ability to understand new information. The extraneous cognitive load refers to the pedagogical procedures and can make a task more difficult in ways that do not lead to learning. Germane cognitive load enhances learning by construction and automation of schemas, which are the mental structures to organise knowledge in longterm memory.

In addition, a flipped classroom can provide the opportunity to use active learning approaches in the classroom, because students can engage with the pre-studied materials using higher-order intellectual skills such as analysis, synthesis and evaluation (Gilboy et al. 2015; Roehl et al. 2013; Tucker 2012). Through this approach, low-level or surface learning (i.e. defining and understanding basic content) can take place outside the classroom, and high-level deeper learning (i.e. apply and evaluate the materials) can be achieved inside the classroom 
(Biggs and Tang 2007; Gilboy et al. 2015; Roach 2014), thereby realising different learning levels according to Bloom's taxonomy (Bloom et al. 1956). Active learning activities, such as brainstorming, case-based instruction, simulation, peer-teaching, and role-play are generally introduced in four instructional approaches: individual activities, paired activities, informal small groups, and cooperative student projects (Zayapragassarazan and Kumar 2012). This active learning approach is specifically appealing to so-called millennial learners (born between 1981 and 1996) who thrive in an ever-changing and dynamic environment (Prensky 2010).

Previous studies have demonstrated the positive effects of the flipped classroom on increased attendance and academic performance (Mason et al. 2013; O'Flaherty and Phillips 2015; Tune et al. 2013). Moreover, a large number of studies report increased student satisfaction with the flipped classroom approach and interactive learning strategies (Critz and Wright 2013; Hung 2014; Yeung and O'Malley 2014). However, some studies did not find positive results for the flipped classroom for student performance (Bossaer et al. 2016; McLaughlin et al. 2013), or reported that students were actually less satisfied with the teaching format than with the traditional lecture (Strayer 2012). A possible explanation for these mixed results is the large variety in implementation strategies used in flipped classroom settings; for instance, there are broad differences in format and structure of study materials, which precludes validation of one consistent implementation approach across different contexts (Bossaer et al. 2016; O'Flaherty and Phillips 2015; Strayer 2012). Moreover, there is a lack of evidence about whether particular demographic factors, such as students' learning preferences, age, sex or economic background affect their experiences with the flipped approach (O'Flaherty and Phillips 2015).

There is also criticism of the methods applied in previous studies to evaluate the effects of flipped classrooms, including that the research was not sufficiently rigorous and that results were rather inconclusive (Goodwin and Miller 2013). While some studies compare improvement in academic performance by considering students' grades, other possible outcomes, such as better learning experiences, problem solving, critical thinking skills and collaboration, could also be included. Furthermore, it is not yet clear how studying in a flipped classroom setting results in better performance because previous studies seldom were specific about which flipped approach, in terms of theoretical foundations or conceptual frameworks, or combination of types of 'blended' learning activities, was used or most effective (O'Flaherty and Phillips 2015; Thai et al. 2017). There is a need for stronger evidence in evaluating student learning and development in the flipped classroom environment.

In this study, we used a mixed-methods research design to explore the possibilities of implementing a flipped classroom in a diverse learning environment and evaluate its effects on different learning processes. We aimed to contribute to existing knowledge about the effectiveness of flipped classroom techniques that can help to address learning diversity among students, in terms of prior knowledge and learning preferences in higher education, by exploring the effect of flipped classrooms on students' learning process and making recommendations for improvement. More specifically, we explored how different flipped approaches, or combination of types of 'blended' learning activities, contributed to the learning process. 


\section{Method}

\section{Design}

In this exploratory study, we evaluated five flipped classroom sessions by using a mixedmethods quantitative and qualitative approach with data triangulation. To collect data, we carried out nonparticipant observation, interviews and focus-group discussions (FGDs), as well as sending out two questionnaires. The first questionnaire was a baseline measurement asking for demographic information (age, sex, prior education and results, disabilities, parents' education, living arrangements), preferred learning styles and learning orientation. The preferred learning style was assessed through a question asking the student to choose one of four learning styles (independently offline, independently online, in a group online, or in a group offline). Learning orientation was assessed by a question asking students to choose from four statements relating to different learning orientation based on Vermunt (2005): self-test, vocational directed, certificate directed and personally interested. The second questionnaire focused on the evaluation of the flipped classrooms by asking about their preparation before class, attendance, appreciation and active participation in class, in addition to whether they felt that they learned more in the flipped classroom than in a traditional classroom. The questionnaires consisted of a mixture of yes/no, multiple-choice and 5-point Likert items.

During the five flipped classroom sessions and four traditional lectures, unstructured observations were made by two and one researcher(s), respectively. During the observations, the researchers reported on attendance, general behaviour and overall participation. Brief semi-structured (group) interviews, in-depth semi-structured interviews and FGDs with students focussed on the positive and negative contributions of the flipped classroom to their learning process. A semi-structured interview with the tutor covered expectations and outcomes concerning student success and educational quality, as well as positive and negative aspects of the flipped classroom approach.

\section{Setting, population and procedure}

Strategic organising (in Dutch: 'Strategisch Organiseren') was an 8-week Master's course in the policy, communication and organisation program in the Faculty of Social Sciences. The aim of the course was to be able to apply knowledge to current topics in the field of strategic management and to develop a critical viewpoint on the scientific literature on strategic organising. Students also became acquainted with theories and practical experiences from the field of consultancy. The course attracts a student population with diverse levels of prior knowledge, because some attended the University of Applied Sciences and followed a pre-Master's program (33\%) and others had Bachelor's degree. The course took place in November and December 2016 and consisted of four traditional lectures (weeks 1, 3, 4-7), five interactive lectures or flipped classrooms (weeks 1-3,6), and three tutorials (weeks 3, 4 and 6). For both the traditional lectures and the flipped classroom sessions, preclass material was provided in the form of prescribed readings. Further, for flipped classrooms, these pre-class reading materials were supplemented with a 120 -min video of the previous year's traditional lecture. Both the traditional lectures and the flipped classrooms were 90-min sessions, with a 15-min break for traditional lectures. The flipped classrooms started with a short recapitulation of the studied material, followed by a group exercise, and ending with student presentations on the group exercise. The design of the in-class 
activities was in line with the flipped the classroom paradigm as described in O'Flaherty and Phillips (2015).

During the first lecture, the flipped classroom approach and our current research were introduced, and students were invited to participate in the research. It was explained that research participation was voluntary and unrelated to course results. Informed consent was signed and a baseline questionnaire was administered. Follow-up questionnaires were collected through GoogleForms immediately after all flipped classrooms; 43 students (aged 22-30 years) completed the baseline questionnaire $(\mathrm{M}=24.30, \mathrm{SD}=1.77)$. For this sample, $58.14 \%$ were women and $21.4 \%$ were the first generation in their family to pursue higher education.

During the flipped classrooms, unstructured observations were made, brief (group-) interviews with students were conducted concerning their experiences in the flipped classroom, and recommendations for FGD topics were made. Students were selected using a convenience sampling method because their availability was the most important criterion. Thirteen students (students 1-13) were briefly questioned for about $10 \mathrm{~min}$ after the interactive lectures. During the course, four other students (students 14-17) were enrolled in two 2-h FGDs. Furthermore, two other students (18-19) were interviewed (for about an hour) during the week after the course ended.

\section{Data analysis}

Survey data were analysed using SPSS software to obtain proportions, means and standard deviations to describe overall trends in responses to the outcome measures. Interview and FGD data were transcribed with Express Transcribe and analysed using MAXQDA software. An inductive thematic analysis was conducted on the qualitative data (interviews, FGDs, open-ended question from the questionnaire) by following the six steps described by Braun and Clarke (2006). One researcher (NG) transcribed and inductively coded the data. Then all codes were examined by the same researcher in order to identify potential themes and to gather data relevant to each theme. In the final phase, the potential themes were checked against the dataset to determine whether they represented the data well and linked up with the research questions. In this phase, themes were refined, which sometimes involved themes being split, combined or discarded. In the final phase, a second researcher (NW) randomly checked the themes against the data set. The researchers resolved discrepancies through discussion and reaching consensus on the themes. During the data analysis, it appeared that data saturation had been reached.

\section{Results}

\section{Diversity in learning styles and motivation}

Students' general learning styles for this sample, as measured by multiple-choice questions administered prior to the flipped classroom, were rather diverse (see Table 1). More than a third of students $(39.5 \%)$ reported that their primary goal was to obtain a degree, whereas $32.6 \%$ felt that the practical relevance of their learning was important. Others were intrinsically motivated and personally interested in the learning material $(25.6 \%)$. One student indicated wanting to study in order to meet other people's expectations. Almost all students found it important to complete their studies on time (95.3\%). In terms of learning styles, 
Table 1 Student learning styles and learning orientation $(N=43)$

\begin{tabular}{ll}
\hline Learning styles and motivation & $\%$ \\
\hline Prior experiences blended learning & \\
Positive & 64.5 \\
Neutral & 35.5 \\
Negative & 0 \\
Learning orientation & \\
Self-test oriented & 2.3 \\
Vocation-directed & 32.6 \\
Certificate-directed & 39.5 \\
Personally interested & 25.6 \\
Learning style & \\
Studying with peers, offline & 54.8 \\
Studying alone, offline & 35.7 \\
Studying alone, online & 9.5 \\
\hline
\end{tabular}

most students $(54.8 \%)$ preferred studying with peers, but more than a third preferred to study alone (35.7\%). A remaining $9.5 \%$ of the students indicated preferring independent study in an online environment. In this sample, $65 \%$ of the students had previous experience of videos replacing traditional lectures and regarded this experience as either positive $(65 \%)$ or neutral $(35 \%)$, but not negative.

\section{Learning experiences in the flipped classroom}

The questionnaire asked students whether the interactive lectures helped them to understand the learning materials better than in traditional lectures. Half of the students $(50 \%)$ agreed that they learned better from the interactive lectures, but $18.2 \%$ disagreed, suggesting that the flipped classroom did not improve everyone's learning outcomes. Below we elaborate on the specific impact of the different learning processes pre-class and in-class according to the students.

\section{Structuring pre-class learning}

For the preparation of the interactive lectures, videos and articles were provided. When comparing the pre-class learning of the flipped classroom with the traditional classroom, more students indicated that they read the prescribed reading materials before the interactive lectures $(75.5 \%)$ than before traditional lectures $(57.8 \%)$. This is supported by the FGDs, during which students indicated that they were more motivated to prepare for the flipped classroom. Students said that they could not follow and contribute to the interactive lecture if they were not sufficiently prepared:

I learned that I need to prepare myself. I fell flat on my face during the second lecture. Then I thought: 'No, it does not work like this. I have to prepare myself'. (student 17, FGD)

The questionnaire indicated that the pre-class videos were more popular than the reading materials, with $81.2 \%$ of the students watching them. Most students watched the videos 
one or two days before class (see Fig. 1). The pre-class videos were appreciated by most students $(60 \%)$, although some were neutral (28.9\%) (Fig. 1) or negative about the videos $(11.1 \%)$, mainly because they were considered too long. The main advantage mentioned by the students in the interviews and FGDs was that the videos allowed them to study at their own pace in their preferred place and at their preferred time of day. Students also reported watching or listening to the lectures at their desk at home or when riding their bicycle on the way to class. Being able to watch the videos at their own pace and place of choice resulted in greater focus, with students being less distracted and more comfortable than in normal lecture settings:

I am a person who is easily distracted and does not want to sit here (read: lecture room) all the time [...] I just prefer working in peace at home. That is what I need. (student 3, short interview)

You can pause whenever you want. So, if you lose concentration, and personally I am easily distracted, I can just take some extra breaks in between. (student 4, short interview)

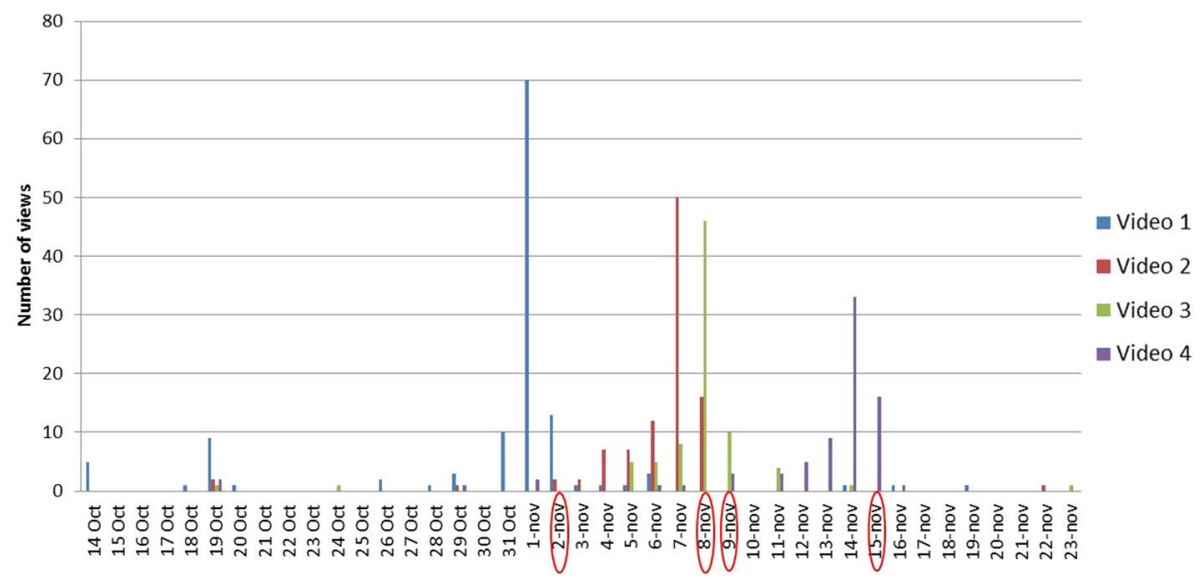

Fig. 1 Summary of student's video viewing behaviour over time in preparation for the lectures on 2, 8, 9 and 15 November 


\section{Structuring in-class learning}

On average, the interactive lectures had higher attendance rates (95.4\%) than did traditional lectures $(88.6 \%)$, with $73.3 \%$ of the students attending all five interactive lectures compared with $53.3 \%$ who attended all four traditional lectures. In the interviews, students explained that the in-class assignments being conducted in groups stimulated them to come to class because they did not want to let their group down:

You have to work together in a group. So you feel like letting your group down if you are not there. (student 2, short interview)

Most students reported in the questionnaire that they actively participated during the interactive lectures (94.4\%). Students explained in the interviews and FGDs that immediate application of the concepts and theories during in-class activities was helpful and working in groups during these assignments facilitated peer-learning and benefitted their learning:

If you are forced to think about the concepts and try to apply them to your own example, it is easier to understand and remember them than during a normal lecture. (student 17, FGD)

In my group, we had a brainstorm session about what an 'open innovation' is [...] then we came to the conclusion that the case studies that we initially selected were not really 'open innovations' at all [...]. During that lecture, we really got to think about the concept. After the lecture, I had a very clear picture in my mind of this concept. (student 3 , short interview)

Although attendance was higher and benefits were reported during the interviews and FGDs, overall appreciation of the interactive lectures measured on a scale from 1 (poor) to 5 (excellent) was the same for the interactive lectures $(\mathrm{M}=3.71, \mathrm{SD}=0.90)$ and the traditional lectures $(\mathrm{M}=3.71, \mathrm{SD}=0.92)$.

\section{Tutor's experience}

From the tutor's perspective, flipping the classroom was a rewarding experience. The tutor found the classroom atmosphere welcoming and engaging. In addition, the interactive lectures were experienced as being less stressful and requiring less preparation than traditional lectures in the long term. She explained that, this year, there was more preparation time needed than for traditional lectures, but she anticipated that this would gradually decline once the interactive course material was available:

It was very pleasant to give the students an assignment. Because it was not just me talking, we had a more mutual relationship, which made the lectures much more enjoyable. (tutor)

Furthermore, the tutor found that overall class performance had improved compared with the previous year when all lectures were conducted in the traditional fashion. The tutor explained that the flipped classroom setting positively contributed to students' performance, because the students were more involved with the study material through the in-class activities:

It has to do with the assignments of the flipped lectures, which were linked to the main assignment $[\ldots]$ This resulted in continued active involvement. (tutor) 


\section{Lessons learned}

Because $18.2 \%$ of students responding to the questionnaire disagreed that they learned better from the interactive lectures, points for improvement were discussed during the interviews and FGDs. The recording of full lectures was considered to be too long. Both students and the tutor recommended that videos replacing traditional lectures needed to be of good quality and appropriate length (neither too long nor too short) and to be up to date. Furthermore, the different pre-class reading and video materials and in-class activities needed to be well aligned with each other and with the examination material. Students were unclear about what was relevant for the examination, because only a small part of the examination material was covered in the flipped classroom. The students were unsure about what they needed to know about the concepts and theories that were not part of the interactive lectures. Students commented that the in-class activities needed to be sufficiently complex and have clear guidelines in order to benefit their learning process and during classroom observations, it also became apparent that some of the exercises were not sufficiently demanding:

During the exercise, several students made jokes about the simplicity of the question.

During the feedback moment, the educator apologised to the students for the level of the questions and highlighted that this is not the level of the examination questions. (observation record during the flipped classroom)

The in-class activities provided insight into students' mastery of the study material. Students explained that a reward for successfully completing the assignments in the flipped the classrooms further stimulated their participation and interaction. Furthermore, the students welcomed feedback from peers and the tutor on their performance during in-class activities:

Sometimes, when a group had to present, I didn't agree with what they were saying. And then the tutor said 'Okay, this was the presentation, we are moving on now' or 'This was the end of the lecture, we are going home now'. That was not satisfactory. (student 14, FGD)

One of the main lessons that the tutor learned was that there was no need for a short recap of the pre-class videos and reading materials, which she and the students explained was a duplication of the pre-class activity. Moreover, the students experienced the recapitulation as rewarding those who had not prepared. Lastly, from a practical planning perspective, students indicated that a traditional lecture room is not the best place to give an interactive lecture and that pre-class self-study time should be considered when scheduling the different interactive lectures, so the students have sufficient preparation time between the flipped lectures.

\section{Discussion}

This study aimed to contribute to existing knowledge about the effectiveness of flipped classroom techniques with a diverse student population in terms of the students' learning process. Below we discuss our findings in light of previous studies and provide an overview of the strengths and limitations of the study. 


\section{Main findings}

More students in the flipped classroom prepared beforehand compared with the traditional lecture, which helped the students to spread the workload and study throughout the course. Some students might already study in this way, but for those with different learning styles who struggle to plan and equally spread the workload over the semester, such an approach could help them to achieve better results. This finding supports previous research demonstrating that pre-class activities in the flipped classroom can help reduce the cognitive load (Abeysekera and Dawson 2015; Clark et al. 2011) and that spacing of learning maximises students' memory retention (Khajah et al. 2014). Moreover, the pre-classroom preparation (videos and reading materials) allowed students to customise or self-regulate the learning process to their personal needs and learning styles (i.e. preferences in terms of study time, place, pace, group vs individual), which could optimise their focus, increase the time spent on each task and subsequently improve the quality of their study.

The positive relationship between self-regulated learning and academic outcomes in traditional classroom settings has been mentioned in previous studies (e.g. Beishuizen and Steffens 2011; Richardson et al. 2012), and these effects have also been found in online settings, although the effect appeared to be weaker (Broadbent and Poon 2015). Recent research acknowledged the important effects of the physical environment on cognitive load and learning (Choi et al. 2014), which was reflected by students in our study preferring the quiet home environment over a busy classroom. Another major benefit was that students with different levels of pre-existing knowledge could get to the same level before entering class, reducing the diversity in knowledge while accommodating for diversity in learning styles.

In-class activities were designed to apply the study materials that students first had to memorise and understand at home. In this way, a deeper conceptual coverage was facilitated and provided a context in which deeper learning could be promoted (Biggs and Tang, 2007). Moreover, the in-class activities in the flipped classroom in our study were mainly based on peer learning. Our research suggested that peer-based learning can be strengthened through the flipped classroom. The group activities could facilitate collaborative learning which, based on the theory of cognitive load, has also been argued to be more effective than individual learning, especially in challenging high-load conditions (Kirschner et al. 2009; Nokes-Malach et al. 2012). This supports our finding that some students did not benefit from the in-class group activities because they perceived it as not being challenging enough. Because group activities are often used in the flipped classroom, it is important to understand that not all collaboration is necessarily beneficial (Nokes-Malach et al. 2015), and that therefore activities should be carefully designed to match prior knowledge and cognitive load. Further research is needed on how to strengthen peer learning in the flipped classroom so that (even) more students benefit.

Furthermore, students reported that in-class activities supported their understanding of the course content. The literature has highlighted that, in flipped classroom settings, students have more time to reflect on their own learning and to make necessary connections with the course content, but it is crucial for optimal learning that the tutor provides feedback on specific aspects of the students' reflection (Roehl et al. 2013). This supports the finding that some students indicated that, for an optimal learning process, they needed feedback from the tutor. Because group activities are frequently used in a flipped classroom, it is important to make time available for the tutor to provide immediate feedback. 
For the tutor, the flipped classroom was a positive experience and she reported being less stressed than usual. This is a huge benefit considering the high levels of burnout in (higher) education (Holmes et al. 2017). Overall, despite these benefits, some students reported that the flipped classroom did not necessarily result in better learning outcomes. Perhaps they had not yet seen the benefits at the time of evaluation, or perhaps flipped classrooms might only benefit a specific type of student, such as someone who is less motivated at the start and does not prefer passive learning through lectures. It must be noted that previous studies have revealed that students are not always able to assess their own performance and identify enhancing learning strategies effectively (Hartwig and Dunlosky 2012; Yan et al. 2014), which could have impacted our findings.

The presence of millennial students in the traditional classroom and their relative intolerance of the traditional one-way learning styles have led to increased attention to alternative approaches (Roehl et al. 2013); the literature on flipped classrooms is booming. At the same time, several lessons learned in our study pointed to the current challenges of implementing flipped classroom in traditional universities. For instance, lecture halls still have fixed seats that all face the same direction, which is not ideal for collaborative learning. Assessments mostly rely on multiple-choice questions and individual essays, but they should be more flexible to align with the learning activities and, for instance, to assess 21 st century skills such as creativity and collaboration (The Partnership for 21 st Century Learning 2015). Besides, during in-class and pre-class learning activities, these more-practical challenges should be considered in developing blended learning and flipped classrooms.

\section{Strengths and limitations}

Our selected mixed-methods approach that combined both quantitative and qualitative data is an appropriate way to evaluate a blended learning program. It not only provides objective data on differences in attendance and participation, but also makes it possible to elaborate on the why and how questions. A strength of our research is that we evaluated the effect of the flipped classroom within one course and one cohort, thus reducing the number of confounding factors. However, because of practical and organisational limitations, the course duration was only eight weeks and only five flipped classroom sessions could be organised. It is questionable whether the students had acquired enough experience with this new learning approach in order to evaluate it. Besides, it was unfortunate that there were relatively few participants, which limited investigating learning outcomes in terms of individual student characteristics (such as learning style and preference) in a quantitative analysis. The sample was too small to investigate any potential differences between the students who did and did not report having benefited from the flipped classroom approach in terms of learning style and preferences. Moreover, in order to properly measure learning styles and preferences, we suggest that future research use reliable questionnaires instead of a single question, which was beyond the scope of the current study. Another limitation was that, because the students who participated in the FGDs were highly motivated and generally reported positive experiences of the flipped classroom, they were not entirely representative of the full cohort. However, a more-diverse student population was included in the short semi-structured (group) interviews which were conducted in class. No major differences between the data gathered through the interviews, questionnaire and FGDs were observed. One major benefit of the course design was that it allowed comparison between traditional lectures and interactive lectures in the same course. This controlled for any possible difference in course content and student population that could affect study outcomes. 
However, the tutor for the traditional lectures was not the same person who facilitated the interactive lectures, which again could have biased outcomes.

\section{Recommendations}

Different activities inside and outside the flipped classroom demonstrated different advantages, although such different activities could interact when combined. For instance, both spacing and variation individually benefit learning, yet a combination of these two can become counterproductive, especially when spaced variations fail to be connected with the original learning (Appleton-Knapp et al. 2005). This underlines the importance of constructive alignment, or the alignment of course activities, assessment and intended outcomes (Biggs and Tang 2007). When more activities are introduced into the flipped classroom, care must be taken to ensure that these activities align well with the original course objectives. In addition, the design of the collaborative learning activities must be considered carefully, making sure it is sufficiently challenging to demand a high cognitive load and connect with students' prior knowledge (Kirschner et al. 2009; Nokes-Malach et al. 2012). This inconsistency and variation in implementation strategies of flipped classrooms also links to the lack of theoretical frameworks in this field, something that could be developed in further studies to enhance consistency across settings. Because this research was conducted with Master's students, who were highly motivated and used to working more independently at an academic level, probably they have better practised self-regulation learning strategies compared with undergraduate students. Flipped classroom research has also been extensive with high school students. Yet, we believe that a relevant next step would be to conduct a similar study with Bachelor's students.

\section{Conclusion}

The flipped classroom trial in the Master's course can be considered a success based on the positive feedback of the diverse group of students and the tutor. The combination of selfregulated pre-class learning by means of video materials and prescribed reading in order to obtain comparable levels of pre-knowledge and understanding, in combination with inclass activities incorporating collaborative learning activities facilitating deeper learning, was considered to have merit, especially in a diverse student population. It was surprising to find that, even though the overall experience was good, not all students agreed that the flipped classroom contributed to their learning outcomes. This finding should be investigated further because outcomes might depend on a student's general learning styles and preferences. In order to facilitate blended learning, such as flipped classrooms, on a larger scale, considerable institutional support is required in order to enable their practical implementation and provide flexible assessments.

Acknowledgements We would like to thank all the students for sharing their experiences and knowledge. Moreover, the authors would like to thank Wanda Konijn who was involved in the design and data collection of this research. This research was supported by a grant from the VU innovation prize 2016 awarded to Marjolein Zweekhorst and her team.

Open Access This article is distributed under the terms of the Creative Commons Attribution 4.0 International License (http://creativecommons.org/licenses/by/4.0/), which permits unrestricted use, distribution, 
and reproduction in any medium, provided you give appropriate credit to the original author(s) and the source, provide a link to the Creative Commons license, and indicate if changes were made.

\section{References}

Abeysekera, L., \& Dawson, P. (2015). Motivation and cognitive load in the flipped classroom: Definition, rationale and a call for research. Higher Education Research \& Development, 34(1), 1-14.

Appleton-Knapp, S. L., Bjork, R. A., \& Wickens, T. D. (2005). Examining the spacing effect in advertising: Encoding variability, retrieval processes, and their interaction. Journal of Consumer Research, 32(2), 266-276.

Beishuizen, J., \& Steffens, K. (2011). A conceptual framework for research on self-regulated learning. In R. Carneiro (Ed.), Self-regulated learning in technology enhanced learning environments (pp. 3-19). Rotterdam: Sense Publishers.

Biggs, J., \& Tang, C. (2007). Teaching for quality learning at university. Berkshire, UK: Open University Press.

Bloom, B. S. (1956). Taxonomy of educational objectives, handbook I: The cognitive domain. New York: David McKay.

Bossaer, J. B., Panus, P., Stewart, D. W., Hagemeier, N. E., \& George, J. (2016). Student performance in a pharmacotherapy oncology module before and after flipping the classroom. American Journal of Pharmaceutical Education, 80(2), 31.

Braun, V., \& Clarke, V. (2006). Using thematic analysis in psychology. Qualitative Research in Psychology, 3(2), 77-101.

Broadbent, J., \& Poon, W. L. (2015). Self-regulated learning strategies \& academic achievement in online higher education learning environments: A systematic review. The Internet and Higher Education, 27, 1-13.

Choi, H. H., Van Merriënboer, J. J., \& Paas, F. (2014). Effects of the physical environment on cognitive load and learning: Towards a new model of cognitive load. Educational Psychology Review, 26(2), 225-244.

Clark, R. C., Nguyen, F., \& Sweller, J. (2011). Efficiency in learning: Evidence-based guidelines to manage cognitive load. San Francisco, CA: Wiley.

Critz, C., \& Wright, D. (2013). Using the flipped classroom in graduate nursing education. Nurse Educator, 38(5), 210-213.

Cruzado, I., \& Román, E. M. (2015). Inverted classroom and its influence on students' attitudes across learning styles. Transportation Research Record, 2480, 38-44.

Gajjar, D. N. B. (2013). The role of technology in 21st century education. International Journal for Research in Education, 2(2), 23-25.

Gilboy, M. B., Heinerichs, S., \& Pazzaglia, G. (2015). Enhancing student engagement using the flipped classroom. Journal of Nutrition Education and Behavior, 47(1), 109-114.

Goodwin, B., \& Miller, K. (2013). Evidence on flipped classrooms is still coming in. Educational Leadership, 70(6), 78-80.

Hartwig, M. K., \& Dunlosky, J. (2012). Study strategies of college students: Are self-testing and scheduling related to achievement? Psychonomic Bulletin \& Review, 19(1), 126-134.

Holmes, E. S., dos Santos, S. R., de Almeida, A. A. F., Candeia, R. M. S., Chaves, L. C. M. R., de Oliveira, A. E. C., et al. (2017). Prevalence of burnout syndrome and factors associated with university teachers. International Archives of Medicine, 10(49), 1-10.

Hung, H. (2014). Flipping the classroom for English language learners to foster active learning. Computer Assisted Language Learning, 28(1), 81-96.

Khajah, M. M., Lindsey, R. V., \& Mozer, M. C. (2014). Maximizing students' retention via spaced review: Practical guidance from computational models of memory. Topics in Cognitive Science, $6(1), 157-169$.

Kirschner, F., Paas, F., \& Kirschner, P. A. (2009). A cognitive load approach to collaborative learning: United brains for complex tasks. Educational Psychology Review, 21(1), 31-42.

Mason, G. S., Shuman, T. R., \& Cook, K. E. (2013). Comparing the effectiveness of an inverted classroom to a traditional classroom in an upper-division engineering course. IEEE Transactions on Education, 56(4), 430-435. 
McLaughlin, J., LaToya, G., Esserman, D., Davidson, C., Glatt, D., Roth, M., et al. (2013). Instructional design and assessment: Pharmacy student engagement, performance, and perception in a flipped satellite classroom. American Journal of Pharmaceutical Education, 77(9), 1-8.

Nokes-Malach, T. J., Meade, M. L., \& Morrow, D. G. (2012). The effect of expertise on collaborative problem solving. Thinking \& Reasoning, 18(1), 32-58.

Nokes-Malach, T. J., Richey, J. E., \& Gadgil, S. (2015). When is it better to learn together? Insights from research on collaborative learning. Educational Psychology Review, 27(4), 645-656.

O'Flaherty, J., \& Phillips, C. (2015). The use of flipped classrooms in higher education: A scoping review. The Internet and Higher Education, 25, 85-95.

Prensky, M. R. (2010). Teaching digital natives: Partnering for real learning. Newbury Park, CA: Corwin.

Richardson, M., Abraham, C., \& Bond, R. (2012). Psychological correlates of university students' academic performance: a systematic review and meta-analysis. Psychological Bulletin, 138(2), 353.

Roach, T. (2014). Student perceptions toward flipped learning: New methods to increase interaction and active learning in economics. International Review of Economics Education, 17, 74-84.

Roehl, A., Reddy, S. L., \& Shannon, G. J. (2013). The flipped classroom: An opportunity to engage millennial students through active learning. Journal of Family and Consumer Sciences, 105(2), 44.

Skill, T. D., \& Young, B. A. (2002). Embracing the hybrid model: Working at the intersections of virtual and physical learning spaces. New Directions for Teaching and Learning, 92, 23-32.

Strayer, J. F. (2012). How learning in an inverted classroom influences cooperation, innovation and task orientation. Learning Environments Research, 15(2), 171-193.

Thai, T. N., De Wever, B., \& Valcke, M. (2017). The impact of a flipped classroom design on learning performance in higher education: Looking for the best 'blend' of lectures and guiding questions with feedback. Computers \& Education, 107, 113-126.

Tucker, B. (2012). The flipped classroom. Education Next, 12(1), 82-83.

Tune, J. D., Sturek, M., \& Basile, D. P. (2013). Flipped classroom model improves graduate student performance in cardiovascular, respiratory, and renal physiology. Advances in Physiology Education, 37(4), 316-320.

UNESCO. (2017). Six ways to ensure higher education leaves no one behind. Paris: Global Education Monitoring Report.

Vermunt, J. D. (2005). Relations between student learning patterns and personal and contextual factors and academic performance. Higher Education, 49, 205-234.

Yan, V. X., Thai, K. P., \& Bjork, R. A. (2014). Habits and beliefs that guide self-regulated learning: Do they vary with mindset? Journal of Applied Research in Memory and Cognition, 3(3), 140-152.

Yeung, K., \& O'Malley, P. (2014). Making 'The Flip' work: Barriers to and implementation strategies for introducing flipped teaching methods into traditional higher education courses. New Directions for Institutional Research, 10(1), 59-63.

Zayapragassarazan, Z., \& Kumar, S. (2012). Active learning methods. NTTC Bulletin, 19(1), 3-5.

Publisher's Note Springer Nature remains neutral with regard to jurisdictional claims in published maps and institutional affiliations. 